\title{
Haemophilia: A disease of women as well
}

\author{
T Naicker, ${ }^{1}$ MB ChB, DCH, FC Paed; C Aldous, ${ }^{2}$ PhD; R Thejpal, ${ }^{1}$ MB ChB, FC Paed, Certificate in Paediatric Clinical \\ Haematology
}

${ }^{1}$ Department of Paediatrics, Inkosi Albert Luthuli Central Hospital, Durban, South Africa
${ }^{2}$ School of Clinical Medicine, University of KwaZulu-Natal, Durban, South Africa

Corresponding author: T Naicker (thironanaicker@gmail.com)

Background. While haemophilia is a disease phenotype in males only, it has an effect on females too. In South Africa, there is no documentation on the views and experiences of haemophilia carrier mothers regarding the disease, or about their response to carrier testing for daughters or other female members of their families. The burden of child care may fall entirely on the mother in some cultures, and having a son with haemophilia may make coping difficult. Knowing their carrier status would allow daughters of carrier mothers to be aware of the chances of themselves having a son with haemophilia. Knowing their own factor levels may also be useful in understanding possible excessive bleeding in themselves.

Objectives. To record the experiences of haemophilia carrier mothers in KwaZulu-Natal and their attitudes and opinions on carrier testing for female members of their families.

Methods. Forty mothers of haemophiliac sons were interviewed using a structured questionnaire specifically designed and tested for this study. Results. From this cohort, there were 21 potential carrier daughters and 25 potential carrier sisters who would be eligible for further testing and counselling. All the study participants expressed their desire to have carrier testing available for female family members. They also expressed their concerns regarding raising a son with haemophilia, including some culture-specific issues.

Conclusion. A diagnosis of haemophilia carriership is seen by mothers of haemophiliac sons as important for female members of their families. A protocol for the care of haemophilia carrier women is therefore necessary.

S Afr J Child Health 2016;10(1):29-32. DOI:10.7196/SAJCH.2016.v10i1.961

Haemophilia $\mathrm{A}$ is the most common inherited bleeding disorder and affects all population groups. It is an X-linked recessive disease, with carrier mothers' sons having a $50 \%$ risk of being affected and the mothers' daughters a $50 \%$ risk of being carriers. ${ }^{[1]}$ The worldwide prevalence of haemophilia $\mathrm{A}$ is estimated to be between 1:5000 and 1:10 000 men. $^{[2]}$ In South Africa (SA), with a population of $\sim 25$ million males, ${ }^{[3]}$ it is estimated that there are between 2500 and 5000 haemophiliac men. There are approximately five potential female carriers for each male with haemophilia. ${ }^{[4]}$ There are therefore between 12500 and 25000 SA women who are carriers.

In carriers, a wide range in factor VIII levels is seen: from very low, resembling affected males, to the upper limit of normal. ${ }^{[5]}$ This range has been attributed to the phenomenon of lyonisation or random $\mathrm{X}$-chromosome inactivation, which takes place early in embryonic life. ${ }^{[6,7]}$ Carrier women could benefit from knowledge of both their genetic (mutation present or not) and their phenotypic (level of plasma factor activity) status. ${ }^{[1,4]}$ It is vital for a woman to know her carrier status for three important reasons:

- The high incidence and intensity of bleeding symptoms of haemophilia A carriers, including bleeding after tooth extraction, easy bruising, postsurgical bleeding and menorrhagia. ${ }^{[8]}$

- The higher risk for primary and secondary postpartum haemorrhage in carrier mothers.

- The risk in carrier mothers for haemorrhage in their newborn male infants who may not yet be diagnosed, especially scalp and intracranial bleeds. ${ }^{[9]}$

Previously, pedigree analysis and clotting factor VIII levels were used to diagnose carriership in haemophilia. ${ }^{[7]}$ However, since the publication of the sequence of the factor VIII gene in 1984, a large number of mutations that cause haemophilia A have been identified and have provided an avenue for confirmatory genetic testing. During the last three decades, genetic counselling, carrier testing and prenatal diagnosis of haemophilia have become an integral part of the comprehensive care of haemophilia. ${ }^{[1,4]}$ Prenatal diagnosis of haemophilia is generally indicated in families with severe or moderate forms of haemophilia. ${ }^{[7,10]}$ Prenatal testing can be done for carrier women if the mutation in the family has been identified. ${ }^{[4]}$

The issue of carrier testing for an X-linked recessive genetic disease in minors is a contentious one, and is normally offered when a patient turns 18 years old. ${ }^{[11]}$ However, with haemophilia, a carrier woman can show symptoms of bleeding and may be clinically affected during her childhood. It has been suggested that it would be in the best interest of the girl child to know her carrier status earlier, as it would be of medical benefit to her. ${ }^{[12]}$

In $\mathrm{SA}$, there is no documentation on the views and experiences of haemophilia carrier mothers regarding the disease or about their response to carrier testing for daughters or other female members of their families. While in some provinces such as Gauteng and the Western Cape carrier testing is provided, mothers at King Edward VIII Hospital, a busy tertiary hospital in KwaZulu-Natal (KZN), have not had access to this service. King Edward VIII Hospital is a public referral centre in the Durban metropolitan area providing regional and tertiary services to Region 1 of KZN and parts of the Eastern Cape. King Edward VIII is a 922-bed hospital with around 360000 outpatients annually. It serves a mainly indigent and isiZuluspeaking population.

\section{Methods}

The authors designed a structured interview questionnaire containing a total of 56 questions, which covered information about general demographics, the carrier mother's affected child, personal information and the mother's views on carrier testing for other women or girls who had not yet had children. The interview questionnaire was piloted at the clinic and amendments were made.

Mothers attending the haemophilia clinic for the first time were excluded because at this initial visit the child is assessed and counselling is conducted by the haemophilia clinic sister. This 
first visit is time consuming and patients need the opportunity to assimilate the newly received information. From March 2012 until April 2014, 40 mothers who attended the haemophilia clinic at King Edward VIII Hospital were interviewed and a pedigree was drawn for each family.

Ethical approval for the study was given by the Biomedical Research and Ethics Committee at the University of KZN. Respondents' informed written consent was obtained for participation in the study and interviews were conducted in private rooms at the study site.

\section{Results \\ Demographics}

The majority of mothers ( $n=27)$ in our study were of African descent, 10 were Indian, 2 coloured and 1 white. The mothers' ages ranged from 23 to 66 years, with the average being 34 years. Only 18 mothers lived in family units together with the child's biological father. The father remained a part of his son's life in 29 cases.

\section{The impact of the diagnosis on the family}

Half of the cohort had a positive family history of haemophilia (Fig. 1). Interestingly, one mother learnt about the illness during a biology class at school and recognised similar symptoms in her brother. She convinced her mother to get her brother investigated, hence uncovering the haemophilia gene in her family.

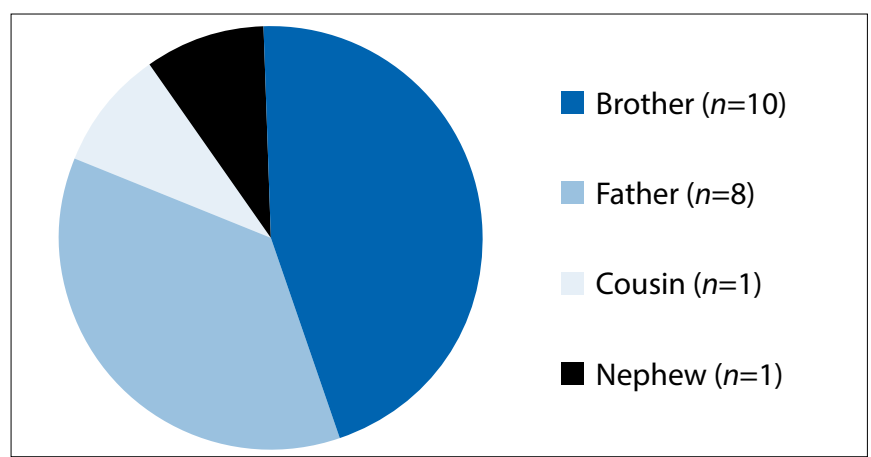

Fig. 1. Family member affected by haemophilia.

At diagnosis, the impact of haemophilia on the family was interpreted as a major stressor in the majority $(n=33)$ of cases. Reasons cited included lack of prior knowledge of haemophilia, that it was a lifelong and chronic illness, and that their child was restricted when playing.

With time, 31 mothers felt that living with haemophilia became more manageable and became less stressful on their family lives. This was accounted for by counselling from a healthcare worker who assisted their understanding of the illness, their learning how to administer factor, and that with time their sons experienced fewer bleeds, which made the situation easier to cope with.

Only 11 mothers with a family history of haemophilia felt that witnessing a relative go through the trials of the disease made it easier to handle the situation with their own son. They felt they were more experienced and educated about haemophilia, that it was a familiar entity to them and that they were emotionally prepared.

Mothers who were not coping stated they feared the sight of blood and were concerned about death, and one mother thought that she needed antidepressants. Mothers reported that siblings felt they were afforded less attention when the ill child needed care.

Many mothers $(n=34)$ experienced financial strain when visiting hospital owing to the high cost of travelling long distances from their home to the clinic.

\section{The impact of haemophilia on the carrier mother}

Menorrhagia was experienced by 22 of the mothers. Only two mothers had been investigated for abnormal bleeding; however, they were still unaware of their results. The majority of mothers $(n=37)$ were informed that they were carriers based on pedigree and not formal molecular testing.

Mothers discovered at an average age of 26 years that they were carriers, but the median age was 30 years. Child-bearing decisions were affected based on this knowledge and 30 mothers stated that they did not intend having further children. Thirty-three women felt that a carrier mother should limit the number of children they bear.

The haemophilia clinic nurse counselled the mothers and discussed the inheritance with them. Despite understanding the genetics of haemophilia, half of the mothers expressed feelings of guilt and felt that they were responsible for giving this illness to their child.

Twenty-seven mothers had first-pregnancy sons, of whom 23 were diagnosed with haemophilia. Eight mothers who had first-pregnancy haemophiliacs had no further children.

In eight families there was another son who was also diagnosed with haemophilia. Three of these boys had died from a haemophiliarelated problem. There was one mother who had three sons and all were haemophiliacs (Table 1).

\section{Table 1. Information from family pedigrees}

\begin{tabular}{ll}
\hline & Carrier $(\mathrm{N}=\mathbf{4 0})$ \\
\hline $\begin{array}{l}\text { Age of haemophilia carrier mother (years), mean } \\
\text { (range) }\end{array}$ & $26(23-66)$ \\
$\begin{array}{l}\text { Age of mother when first child is diagnosed with } \\
\text { haemophilia (years), mean }\end{array}$ & 23 \\
No further children after a haemophiliac son, $n$ & 8 \\
More than one haemophiliac son, $n$ & 8 \\
Potential carrier daughters, $n$ & 21 \\
Potential carrier sisters, $n$ & 25 \\
Obligate carrier sisters (haemophiliac fathers), $n$ & 5
\end{tabular}

Most mothers $(n=34)$ perceived their sons to be normal with a 'blood disorder'. Six mothers commented: 'He is delicate, he needs to be careful and he is restricted from doing things other normal children do.'

Most mothers $(n=31)$ received emotional support from the child's father following the diagnosis. Even though half of the mothers were aware of a family history of haemophilia, only two fathers were aware of the risk of having a haemophiliac son prior to pregnancy. Six women in our cohort experienced negative comments from the child's father and in-laws regarding assignment of blame, such as 'This never existed in our family until you came along.' Four mothers were blamed by their partners for bringing this illness into the family. Two of these fathers subsequently abandoned their families as they could not cope with their sons' illness.

\section{Use of traditional medicine}

Eleven families felt that the child was bewitched because he suffered nose bleeds or swollen joints. Eight families initially used traditional/ herbal medication to treat the bleeding.

\section{The affected child}

The average age of diagnosis of the haemophiliac sons was 24 (range 0 - 72) months. Of the four babies diagnosed in the neonatal period, three had positive family histories, which resulted in earlier detection; the other was detected post circumcision. Of the 29 haemophiliacs of school-going age, only 15 were in the correct grade for their age. 
Joint and mouth bleeds, as well as extensive bruising, were the most common first presentations. Over the years, 12 boys had more than 10 hospital admissions each, often for joint-related bleeds. Four boys had never been admitted prior to the time of this study.

\section{Mothers' attitudes to carrier testing}

All the mothers felt that carrier testing is of vital importance. Being equipped with the knowledge of one's carrier status of haemophilia allows a carrier to make informed choices regarding future child bearing. When questioned about their advice to potential carrier daughters regarding starting a family, nine mothers would discourage their daughters from having children, and seven would advise them to limit the number of children to a maximum of two. The rest of the mothers felt child-bearing decisions should be their daughters' own choice, after knowing their carrier status.

Thirty mothers felt other females in their family may want to be tested for carriership. Twenty-one mothers had potential carrier daughters and there were 25 possible carrier sisters. Only six respondents' families had ever discussed carrier testing before and these women were open to carrier testing. Over half $(n=25)$ of the mothers felt that a carrier should not be forced to take a test and that it should be a carrier's right to choose if she wanted to be tested.

The age cited by just over half $(n=21)$ the mothers as the best time to undergo carrier testing is during one's teenage years, with 16 favouring early childhood followed by three who favoured adulthood. The overwhelming reason was that a carrier should know her status prior to any pregnancy.

Antenatal testing via amniocentesis was felt to be a positive intervention and almost all $(n=37)$ mothers would advise relatives to have such testing done. Reasons given included knowing their son is affected prior to delivery would enable them to make decisions regarding continuation of the pregnancy, although the majority of mothers $(n=33)$ would not consider termination of pregnancy for a severe haemophiliac fetus.

\section{Discussion}

The purpose of the study was to document the experiences of haemophilia carrier mothers at a busy tertiary hospital in KZN regarding carrier testing, prenatal diagnosis, raising a haemophiliac son, genetic counselling and the effect of being a carrier. We also obtained their opinion on potential carrier testing with particular regard to their daughters and other possible carriers.

Gender plays an important role in shaping the burden of care in the African context. Women are more likely than men to take on caregiving activities. ${ }^{[13]}$ In SA, most mothers assume almost exclusive responsibility for child rearing and households. In our study, only 29 fathers were involved in their sons' lives. During the interview process, only one father accompanied the mother to the Haemophilia Clinic for treatment or counselling. Support from partners is vital to coping and living with haemophilia. Parents' quality of life can be shaped by perceived emotional strains and worries concerning the child's future. Mothers who are not supported by their partners risk loss of quality of life. ${ }^{[14]}$

The decision not to have more children draws attention to the emotional, psychological and physical burden of the disease on a carrier. This finding is similar to that of a Swedish study by Tedgård et al. ${ }^{[15]}$ where carriers who did not choose prenatal diagnosis often abstained from further pregnancies after the birth of a haemophiliac child, and they had significantly fewer children than the remainder of the carriers. ${ }^{[15]}$

In SA, preconception genetic counselling is rare. Twenty mothers in our cohort had a family history of haemophilia; however, only two chose to disclose this information to their partners. One has to question whether the genetic counselling information was correctly relayed to members of the affected family or influenced by other factors related to disclosure. Many mothers may not have considered themselves to be at risk of conceiving a child with haemophilia, despite knowing about the family history. The average age of finding out they were carriers was 26 years old, usually after the diagnosis in their son was made.

In addition to genetic counselling, psychological counselling by a psychologist or social worker needs to be offered to mothers and families who are grappling with the chronic nature of the illness in their sons. Nine mothers felt that they were not coping with their boys' haemophilia years after the initial diagnosis was made. Family counselling would also benefit siblings who feel marginalised, as less time was dedicated to their needs. Families, including siblings, need specific interventions to assist with the emotional, financial and physical stress that they experience when dealing with a chronically ill child. ${ }^{[16]}$

Mothers need to equip themselves with knowledge about the illness and how it affects their families. In our clinic, emphasis was placed on treatment in the affected haemophiliac, and not on prevention or detection in future generations. A paradigm shift needs to occur among carrier mothers.

From the international literature, it has been cited that $89 \%$ of women considered carrier testing to be a positive thing and $49 \%$ felt that the best time to test would be in teenage years. ${ }^{[1]}$ In our cohort, all women (100\%) felt carrier testing to be of vital importance and 53\% felt that the teenage years would be most suitable to have the test.

\section{Conclusion}

Being a haemophilia carrier mother affects many aspects of life, own health in terms of possible excessive bleeding, reproductive choices and perception of self as a responsible parent. A young carrier female should receive education and genetic counselling about the illness, reproductive choices and future prospects of raising a child with haemophilia.

Our study highlights the need for accessible carrier testing in KZN We need to educate the community about the benefits of carrier testing and implement a strategy to improve carrier screening and detection in KZN.

\section{Recommendations}

As a result of the study we have developed the following recommendations for a protocol for the care of potential carrier haemophilia women.

Once a diagnosis of haemophilia is made in her child, the mother should receive the following:

1. Counselling from trained medical staff regarding the condition, the inheritance pattern, how it affects her son and other family members

2. Blood tests for factor levels and molecular carrier detection in the mother (her genotype)

3. A pedigree/family tree

4. A contact and carrier tracing card which she can give to other potential carrier women in her family, enabling and empowering them to get tested

5. Once her results are ready, counselling on the implications regarding bleeding, child bearing, etc.

6. Referral to a local haemophilia support group

7. Access to prenatal counselling for haemophilia carriers and testing when required at a comprehensive haemophilia care clinic.

Acknowledgments. We acknowledge Prof. Miriam Adhikari for reviewing the article.

\section{References}

1. Ranta S, Lehesjoki AE. Hemophilia A: Experiences and attitudes of mothers, sisters and daughters. Pedriatr Hematol Onc 1994;11(4):387-397. 
2. National Human Genome Research Institute. Learning About Haemophilia. September 2011. http://www.genome.gov/20019697 (accessed 13 August 2014).

3. Statistics South Africa. Mid-year Population Estimates. July 2014. http://www. statssa.co.za (accessed 30 March 2015). \$

4. Street AM, Ljung R, Lavery SA. Management of carriers and babies with haemophilia. Haemophilia 2008;14(Suppl 3):181-187. [http://dx.doi.org/10.1111/ j.1365-2516.2008.01721.x]

5. Ay C, Thom K, Abu-Hamdeh F, et al. Determinants of factor VIII plasma levels in carriers of haemophilia A and in control women. Haemophilia 2010;16(1):111-117. [http://dx.doi.org/10.1111/j.1365-2516.2009.02108.x]

6. Renault NK, Dyack S, Dobson MJ, Costa T, Lam WL, Greer WL. Heritable skewed X-chromosome inactivation leads to haemophilia A expression in heterozygous females. Eur J Hum Genet 2007;15(6):628-637. [http://dx.doi. org/10.1038/sj.ejhg.5201799]

7. Husain N. Carrier analysis for hemophilia A: Ideal versus acceptable. Expert Rev Mol Diagn 2009;9(3):203-207. [http://dx.doi.org/0.1586/erm.09.3]

8. Miesbach W, Alesci S, Geisen C, Oldenburg J. Association between phenotype and genotype in carriers of haemophilia A. Haemophilia 2011;17(2):246-251. [http://dx.doi.org/10.1111/j.1365-2516.2010.02426.x]

9. Hooper WC, Miller CH, Key NS. Complications associated with carrier status among people with blood disorders: A commentary. Am J Prev Med 2010;38(Suppl 4):S456-S458. [http://dx.doi.org/10.1016/j.amepre.2010.01.009]
10. Ghosh K, Shetty S, Tulsiani M. Evolution of prenatal diagnostic techniques from phenotypic diagnosis to gene arrays: Its likely impact on prenatal diagnosis of hemophilia. Clin Appl Thromb Hemost 2009;15(3):277-282.

11. Borry P, Fryns JP, Schotsmans P, Dierickx K. Carrier testing in minors: A systematic review of guidelines and position papers. Eur J Hum Genet 2006;14(2):133-138. [http://dx.doi.org/10.1177/1076029607308870]

12. Borry P, Evers-Kiebooms G, Cornel MC, Clarke A, Dierickx K on behalf of the Public and Professional Policy Committee (PPPC) of the European Society of Human Genetics. Genetic testing in asymptomatic minors. Eur J Hum Genet 2009;17:711-719. [http://dx.doi.org/10.1038/ejhg.2009.25]

13. Schatz EJ. 'Taking care of my own blood': Older women's relationships to their households in rural South Africa. Scand J Public Health 2007;69:147-154. [http://dx.doi.org/10.1080/14034950701355676]

14. Wiedebusch S, Pollmann H, Siegmund B, Muthny FA. Quality of life, psychosocial strains and coping in parents of children with haemophilia. Haemophilia 2008;14(5):1014-1022. [http://dx.doi.org/10.1111/j.13652516.2008.01803.x]

15. Tedgård U, Ljung R, McNeil TF. Reproductive choices of haemophilia carriers. Br J Haematol 1999;106(2):421-426.

16. Anderson T, Davis C. Evidence-based practice with families of chronically ill children: A critical literature review. J Evid Based Soc Work 2011;8(4):416-425. [http://dx.doi.org/10.1080/15433710903269172 